\title{
UPAKARA CARU MANCA MEBAYANG-BAYANG KEBO DI PURA MERU LINGKUNGAN KARANG KECICANG CAKRANEGARA (KAJIAN BENTUK, FUNGSI, DAN MAKNA)
}

\author{
Fuad Noorzeha \\ Universitas Kusuma Husada \\ zehaphilosophy@gmail.com \\ I Gede Wardana \\ IAHN Gde Pudja Mataram \\ wardanaa.igd@gmail.com
}

\begin{abstract}
Abstrak
Pelaksanaan upacara dapat dikatakan menjadi salah satu hal sentral dalam praktik keagamaan Hindu. Hal ini mengingat upacara menjadi bagian dari Tri Karangka Dasar agama Hindu setelah Tattwa dan Susila. Keutamaan dari upacara dalam keagamaan Hindu, menjelaskan penting nya kajian yang bertujuan menggali makna tiap upacara yang dilakukan. Penulis berupaya untuk menggali salah satu upacara dalam agama Hindu yaitu upacara Caru Manca Mebayang-bayang Kebo di Pura Meru, dengan melakukan metode wawancara dan observasi dari pelaksanaan upacara tersebut. Kesimpulan yang didapat dari penelitian ini adalah: (1) Caru Manca Mebayang-bayang Kebo adalah salah satu prosesi Bhuta Yadnya yang merupakan koban suci kepada mahluk halus, (2) fungsi dari pelaksanaan Caru manca Mebayang-bayang adalah untuk penyucian diri dan menjaga harmoni kehidupan, (3) manfaat dari pelaksanaanya adalah agar manusia dapat menyadari sifat butha kala pada diri nya, dan berusaha untuk menetralisir hal tersebut dalam upacara dan menekannya dalam perilaku sehari.
\end{abstract}

Kata Kunci: Caru, Pura Meru, Hindu

\section{Pendahuluan}

Agama Hindu diwahyukan oleh Ida Sang Hyang Widhi Wasa melalui para Rsi.

Para Rsi penerima wahyu tersebut menuangkan seluruh ajaran suci itu dalam suatu kerangka dasar yang disebut Tri Kerangka Dasar Agama Hindu (Somawati dan Made, 2019), yaitu:

1. Tattwa atau Filsafat merupakan inti dari ajaran Agama Hindu yang menguraikan suatu kebenaran yang bersifat hakiki.

2. Susila atau etika yang menguraikan perilaku yang baik dan benar di masyarakat.

3. Upacara atau ritual yang menguraikan tentang tata cara menunjukkan rasa bakti kepada Sang Pencipta dengan menggunakan sarana.

Ketiga kerangka dasar ini mempunyai jalinan yang sangat erat dan tidak bisa dipisahkan satu dengan yang lainnya dalam Agama Hindu. Tatwa itu sebagai kepala, 
Susila itu sebagai hati dan Upacara itu sebagai tangan dan kaki agama (Sudharta, 2001: 5). Upacara atau ritual adalah merupakan suatu wujud yang nyata dari Agama Hindu sebagai rasa Bhakti yang dilakukan atas dasar tulus ikhlas yang disebut Yajna.Pelaksanaan Yajna terkait dengan konsep Tri Rnam yaitu tiga jenis hutang yang harus kita bayar yang bersifat kerohanian dan spiritual. Tiga jenis hutang menurut ajaran Agama Hindu (Yagnyawati, 2019: 92), adalah sebagai berikut ;

1. Dewa Rnam yaitu hutang kepada Dewa atau Tuhan, karena semua yang ada di alam semesta ini bersumber dan berasal dari Beliau yaitu Tuhan itu sendiri.

2. Pitra Rnam yaitu hutang kelahiran karena leluhur telah memberikan badan ini.

3. Rsi Rnam yaitu hutangilmu pengetahuan kepada para Rsi dan guru, karena telah memberikan kita ilmu pengetahuan yang bersifat suci sehingga kita memiliki wiweka atau wawasan yang luas dalam berpikir.

Dari Tri Rnam tersebut maka timbullah pelaksanaan upacara Yajnayang dilaksanakan dengan penuh hormat dan rasa terima kasih dalam bentuk Panca Yajna. Panca Yajna adalah lima macam korban suci yang bersifat tulus ikhlas tanpa pamrih yang dapat menciptakan keharmonisan dalam hidup ini (Puja, 1983: 14). Hal ini dapat diuraikan sebagai berikut :(1) Dewa Yajna adalah suatu korban suci yang bersifat tulus iklas tanpa pamrih yang ditujukan kepada Ida Sang Hyang Widhi Wasa dan sinar-sinar suci-Nya yang disebut Dewa-Dewi. (2) Pitra Yajna adalah korban suci yang ditujukan kepada Pitra atau Roh leluhur.(3) RsiYajna adalah korban suci yang ditujukan kepada para Rsi dan guru. (4) Manusia Yajna adalah korban suci yang ditujukan kepada sesama manusia.(5) Bhuta Yajna adalah korban suci yang ditujukan kepada Bhuta Kala yaitu Roh jahat yang sering menganggu kehidupan manusia (Putra, 1993 :8).

Bagi masyarakat Hindu yang ada di Lombok, alam semesta adalah satu kesatuan yang hidup. Anggapan seperti ini berarti bahwa di samping dari manusia "pribadi" maka akan menerima alam semesta sebagai yang dipribadikan. Pandangan subjektif terhadap alam, menyebabkan antara manusia dengan alam kualitas hubungannya adalah horizontal. Maksudnya antara manusia dengan alam terjadi hubungan secara timbal balik (interdependency). Alam tidak dapat terproses dengan baik tanpa manusia, demikian juga manusia tidak dapat hidup tanpa alam. Manusia dapat dihancurkan oleh alam, namun begitu juga alam dapat dihancurkan oleh manusia. Dalam hal ini lah manusia perlu melakukan penyesuaian diri dengan kondisi alam tempat hidup nya, dan relasi antara manusia dengan 
alam itu lah yang menurut Suryosumunar (2021: 38-46) menjadi dasar muncul nya kebudayaan yang terdapat tradisi-tradisi di dalam nya. Bagaimanapun juga manusia dengan alam senantiasa memiliki relasi saling kait mengait satu sama lain, dan bahkan dalam ajaran Hindu, manusia dipahami sebagai alam kecil (mikrokosmos).

Kurang pemahaman disebabkan oleh rumit dan luas nya masalah upacara yadnya itu, tetapi banyak juga disebabkan oleh faktor-faktor lain seperti : lontar-lontar banyak bersifat ajawera (tidak boleh diketahui oleh orang banyak) dan belum diterjemahkan ke dalam Bahasa Indonesia, masih banyak mengikuti Sima yaitu kebiasaan setempat yang berbeda. Sejak runtuhnya kerajaan Majapahit abad kelima belas (15) dan munculnya pengaruh Islam dikatakan Agama Hindu di Indonesia mengalami masa kemerosotan, selama itu pula pengajaran Agama Hindu bersifat tradisional, hidup dan berkembang di beberapa daerah saja. Baru beberapa tahun kemudian agama Hindu diajarkan pada sekolah-sekolah, seolah-olah Agama Hindu merupakan pelajaran baru.

Pelaksanaan yadnya dapat dikategorikan menjadi bagian yang disebut dengan Panca Yadnya artinya lima korban suci yang dilakukan dengan tulus ikhlas dan berdasarkan dengan Dharma. Adapun pembagian Panca Yadnya tersebut menurut (Suamba,1996 : 26) yaitu :

1. Dewa Yadnya (korban untuk para Dewa/Tuhan), yang menggerakan alam semesta beserta isinya sehingga berfungsi sebagaimana mestinya.

2. Yadnya (korban untuk mahluk-mahluk yang lebih rendah dari manusia), dengan cara menyuguhkan makanan maupun minuman.

3. Pitra Yadnya (korban untuk para leluhur) suatu ungkapan terima kasih kepada leluhur.

4. Manusia Yadnya (korban untuk sesama manusia), dengan cara memberikan pelayanan kepada semua manusia.

5. Rsi Yadnya (korban untuk para Rsi dan pendidik), dengan cara mempelajari kitabkitab Suci serta menyebarkan ajaran-ajaran sucinya.

Kata Bhuta berasal dari bahasa sansekerta dari urat kata Bhu artinya ada (Astra,2000:275), sedangkan Dalam kamus Jawa Kuno Indonesia Bhuta diartikan sebagai mahluk hidup raksasa, sesuatu wujud yang mengerikan; roh jahat; hawa nafsu (Mardiwarsito, 1981:130). Secara filosofis Bhuta itu adalah merupakan kekuatan negatif yang timbul karena tidak adanya keharmonisan dan keseimbangan antar masing-masing unsur Panca Maha Bhuta yang menjadikan alam ini. Ketidakharmonisan menimbulkan 
kekeruhan suasana yang terjadi pada bhuwana alit (manusia) dan Bhuana Agung (alam semesta) tempat semua mahluk hidup.

Apabila hubungan antara makrokosmos dengan mikrokosmos tidak harmonis akan menimbulkan adanya bencana alam, seperti banjir, tanah longsor, angin ribut, dan kematian di sana sini, yang menimpa daerah perkotaan, pegunungan, dan daerah pedesaan, sehingga masyarakat tidak merasakan ketentraman. Itulah sebabnya manusia senantiasa menjaga keharmonisan kedua kosmos itu, menurut Agama Hindu berupa caru untuk mengharmoniskan bumi atau alam sekitar dengan lingkungan, maka dilaksanakan Upakara Caru Manca Mebayang-Bayang Kebo pada saat Pujawali di Pura Meru Lingkungan Karang Kecicang.

Upakara caru Manca Mebayang-Bayang kebo yang dilaksanakan di Pura Meru Karang Kecicang sebenarnya sudah dari dulu dilaksanakan oleh masyarakat, namun masyarakat luas belum banyak memahami apa itu Upakara Caru Manca MebayangBayang Kebo. Upakara Caru Manca Mebayang-Bayang Kebo merupakan suatu korban suci kepada unsur alam baik yang berwujud nyata maupun tidak nyata yang dilaksanakan di Pura Meru Karang Kecicang untuk "menetralisir" pengaruh negatif dari mahluk Bhuta. upakara Caru Manca Mebayang-Bayang Kebo merupakan langkah ritual dan mengandung muatan kontekstual yang diaktualisasikan dengan langkah nyata menjaga keharmonisan antar Bhuwana Agung dengan Bhuwana Alit sehingga bisa mencapai keharmonisan manusia.

Tujuan yang ingin dicapai ada dua segi kehidupan yaitu segi kehidupan lahir dan batin. Tujuan yang pertama pada hakekatnya menginginkan kemakmuran masyarakat atau kesejahteraan duniawi, sedangkan tujuan yang kedua menginginkan kebahagiaan batin sebagai landasan untuk menuju kebahagiaan jiwa yang kekal dan abadi yang disebut "moksa". Dalam bentuk yang lebih hakiki, hal tersebut dirumuskan dalam Kitab Suci berbunyi " Moksartham Jagadhita Ca Iti Dharma" yang artinya "tujuan hidup manusia adalah mencapai kesejahteraan jasmani dan kebahagian rohani secara selaras dan seimbang" (Mantra, 1992:10). Sesuai dengan hukum rta, maka perlu diyakini bahwa dunia ini ada yang mengatur dan menciptakannya, dan manusia sudah sewajarnya pula saling mencintai sesama ciptaan Tuhan. Umat Hindu meyakini bahwa hubungan antar Bhuwana alit dengan Bhuwana agung yaitu hubungan manusia dengan alam semesta itu harus serasi, selaras, dan seimbang. Keselarasan antar kedua Bhuwana itu merupakan landasan pokok untuk memperoleh kesejahteraan lahir dan batin. 
Alam merupakan bagian yang tak terpisahkan dari suatu ekosistem, yaitu tempat berlangsungnya hubungan timbal balik antar mahluk hidup dan faktor alam.Antara alam dan manusia harus saling menjaga kehidupan yang berdasarkan Yajna. Kemajuan ilmu pengetahuan dan teknologi dimana pendidikan modern sudah meresap pada masyarakat sehingga pemikiran-pemikiran modern tersebut memberi pengaruh alam pikiran masyarakat. Salah satu Dampak pikiran modern yang adalah pemikiran rasional.Setiap masalah selalu dipecahkan atas dasar rasio dan masuk akal hingga dapat dipahami makna dan fungsi dilaksanakannya upacara yang dimaksud.

Upacara-upacara agama secara rutin masih dilakukan, namun apa sesungguhnya makna upacara yang dimaksud dan apa tujuannya, ternyata banyak kalangan umat Hindu yang tidak tahu. Wikraman (1998:1) menyebutkan ternyata banyak kalangan umat Hindu jika ditanya tentang makna dan tujuan Upakara jawabannya Mula Keto. Hal ini tidak boleh dibiarkan terus, lebih-lebih dalam memasuki era globalisasi. Upacaraupacara tersebut perlu diungkap dan digali makna nya agar mudah dipahami dan dihayati terutama oleh umat Hindu sendiri. Bila hal ini tidak dilakukan, timbul kekhawatiran nantinya tentang keberlangsungan pelaksanaan upacara yang lepas dari makna dan tujuan nya. Salah satu pelaksanaan upacara tersebut adalah Caru Manca Mebayang-bayang Kebo di Pura Meru lingkungan Karang Kecicang yang tentunya perlu lebih dipahami bentuk, fungsi dan makna nya. Hal tersebut menarik minat penulis untuk meneliti lebih dalam terkait makna dan manfaat dari pelaksanaan Upakara Caru Manca Mebayang-bayang Kebo tersebut, karena peribadatan umat Hindu di lokasi tersebut dapat menjadi sampel yang mewakili umat Hindu di kota Mataram.

\section{Metodologi Penelitian}

Penelitian ini merupakan penelitian dengan pendekatan kualitatif, Mulai dari gagasan dan ide penelitian, pengumpulan data, menjawab permasalahan dan tujuan penelitian serta melakukan katagorisasi. Hal tersebut bertujuan untuk mendapatkan temuan-temuan empiris yang dapat didiskripsikan secara lebih rinci, lebih jelas, lebih akurat. Dalam hal ini temuan temuan empiris tersebut terkait fungsi dan makna Upakara Caru Manca Mebayang-bayang Kebo dilingkungan Karang Kecicang Cakranegara. Dimana dalam proses pengumpulan data peneliti menggunakan beberapa metode yaitu:

1. Observasi, Observasi yang dimaksud adalah suatu pengamatan lansung terhadap 
objek-objek yang diteliti dan mengadakan pencatatan secara sistematika fenomena yang diselidiki, yaitu upacara Caru Manca Mbayang-bayang Kebo di lingkungan Karang Kecicang Cakranegara.

2. Wawancara, dilakukan terhadap sejumlah informan kunci yang memiliki pengetahuan yang banyak dan mendalam mengenai Upakara Caru Kebo di Jaba Pura Meru Karang Kecicang Kelurahan Cakranegara Selatan Kecamatan Cakranegara Kota Mataram. Wawancara dilakukan, baik dalam bentuk wawancara individu maupun bentuk wawancara kelompok.

\section{Hasil dan Pembahasan}

\section{Upacara Caru}

Upakara Bhuta Yajna yang lazimnya di Bali dan di Lombok di sebut Tawur atau Caru (Surpha, 1979 :19). Kata Tawur berarti membayar.Dalam kamus Kawi Indonesia kata Tawur berarti korban selamatan (Wojowasito, 1977:266). Membayar berarti mengorbankan sebagian dari milik kita yang dianugrahkan oleh Sang Pencipta.Manusia sepatutnya ingat dan sadar bahwa manusia memiliki hutang kepada Ida Sang Hyang Widhi Wasa, oleh karena itu manusia berkewajiban pula untuk mengembalikannya.Setiap hari selama setahun manusia terus menerusmengambil isi bumi ini, maka sudah sewajarnya mengembalikannya, secara simbolis pengembalian ini berupa persembahan Caru .

Caru adalah nama jenis Upakara, banten atau sesajen yang dipergunakan dalam upacara Bhuta Yajna. Kata caru berarti : enak, manis, sangat menarik, bila dihayati secara mendalam dari pengertian kata enak, manis, sangat menarik terkandung kata harmonis, serasi atau seimbang, yang dalam Bahasa Bali, disebut Pangus atau Adung, sehingga dapat disimpulkan bahwa caru atau BhutaYajna adalah Yajna dari manusia untuk mewujudkan keharmonisan di alam semesta, yaitu Bhuana Alit dan Bhuana Agung (Arwati, 1982:3). Kekuatan alam yang baik digambarkan dengan dewa-dewa, walaupun kata dewa berarti sinar suci dari Tuhan, sedangkan kekuatan alam yang merusak kehidupan di alam semesta ini, yang belum tentu merusak tetapi selalu dihubungkan dengan kekuatan-kekuatan yang bersifat negatif. Untuk itu manusia berkewajiban menjaga keharmonisan alam semesta ini, agar selalu memberi manfaat dalam kehidupan (Putra, 1984:39). Keharmonisan itu dijaga dengan melakukan korban suci berupa Bhuta Yajna. Umumnya bentuk korban suci ini berupa Bebali yakni jenis Upakara yang terdiri dari 2 (dua) nasi atau segahan yang 
dilengkapi dengan lauk dan daging, serta minuman yang mengandung alkohol (Wikarma, 1998:7). Mengenai bentuk persembahan Yajna menurut Manawa Dharmasastra Bab III, sloka 74 sebagai berikut :

"Japo 'huto huto homah

Pruhuto bhautiko balih,

Brhamyam hutam dwija

Gryarca pracitam pitr tarpanam"

Artinya:

Japo adalah pengucapan doa dari Weda, huta persembahyangan homa, ahuta adalah upacara bali yang dihalurkan di atas tanah kepada para Bhuta, Brahma Huta yaitu menerima tetap para brahmana secara hormat setiap menghaturkan kepada api yang ada dalam tubuh Brahman dan Prasita adalah persembahan tarpana kepada para pitara. (Puja 2002 : 152)

Macam dan bentuk-bentuk caru sangat beragam, hal tersebut terkait dengan jenis binatang yang dikorbankan dan tujuan dari pelaksanaan dari caru tersebut..

a. Wikraman, (1998: 15 ), menurut obyeknya Caru terdiri dari tiga jenis yaitu :

1) Caru untuk mengharmoniskan bumi atau alam sekitar denganlingkungannya yang disebutBhumi Suddha.

2) Caru untuk menyeimbangkan atau mengharmoniskan ruang dan waktuserta sesuai dengan musim atau masa yang disebutCaru Sasih.

3) Caru untuk mengharmoniskan perilaku manusia atas pengaruh kelahiranyang disebutCaru Oton, atau bea kalaning rare metu.

b. Wikarman, (1998: 16) Sesuai dengan binatang yang dipergunakan, maka upacara Bhuta Yajna dapat dibagi menjadi tiga tingkatan.

1) Tingkatan upacara yang kecil (nista), biasanya berupa nasi (segehan) seperti Segehan Cacahan, Segehan Kepel, Segehan Mancawarna dan Segehan Agung dengan daging jejeroan.

2) Tingkatan Upakara yang sedang (madya )menggunakan ayam dan itik. Upakara-Upakaranya disebut dengan Caru seperti Caru Eka Sata, Caru Mancawarna, Caru Panca Sata hingga Caru Panca Sanak Madurga.

3) Tingkatan yang besar atau utama Upakaranya disebut dengan Tawur, seperti Manca Kelud, yaitu Caru yang dasarnya adalah Manca Sanak ditambah dengan angsa dan kambing. Bila Caru ini mempergunakan seekor kerbau, maka Tawur itu disebut Labuh Gentuh atau Tawur Agung. Lebih besar lagi terdapat Tawur Panca Walikarama hingga Eka Dasa Ludra 
c. Berdasarkan ruang lingkup serta kegunaannya jenis-jenis Caru dan Tawur dibedakan menjadi :

1) Caru yang sering dilaksanakan dan dipergunakan dalam berbagai kegiatan untuk umum atau jagat antara lain:

a. Caru Eka Sato

b. Caru Puncu Suto

c. Caru Panca Sanak

d. Caru Panca Kelud

e. TawurLabuh Gentuh

f. Tawur Panca Bali Krama

g. TawurEka Dasa Ludra

2) Caru secara khusus antara lain yaitu :

b. Caru Dewasa Ala

c. CaruRsi Gana

d. Caru Kadurmanggalaan

e. Caru Kegeringan

f. Caru Penolak Merana

g. Caru Sasih

3) Caru Palemahan dimaksudkan adalah upacara untuk mengharmoniskan areal pelataran atau wilayah. Areal atau wilayah yang dimaksud adalah Wilayah hunian, baik hunian manusia, binatang, tumbuh-tumbuhan, bahkan juga termasuk areal yang ditepati para dewa-dewa, yang kita kenal dengan parahyangan.

Besar kecilnya palemahan dan juga tingkatan palemahanakanmenentukan besar kecilnya Caru yang dipergunakan utuk menyucikan palemahan itu. Palemahan terdiri dari :

a. Palemahan Karang contohnya Caru Eka Sata.

b. Palemahan banjar contohnya CaruPanca Sata.

c. Palemahan Desa Adat contohnya Caru Panca Sanak.

d. Parahyangan contohnya Caru Panca Sanak dengan hewan korban seekor godel (Caru Sanak Magodel).

Pada kenyataannya Umat Hindu dalam kehidupannya sehari-hari di Bali dan Lombok 
khususnya tidak pernah lepas dari kegiatan Yajna, baik Yajna yang tergolong nista, madya maupun yang utama.Pembagian atau kriteria nista, madya maupun utama ini agar umat dapat melaksanakan Yajna sesuai dengan kemampuan masing-masing. Yajna ialah korban Suci yang dilandasi dengan hati yang tulus iklas serta merupakan salah satu alat penyangga dunia, sebagaimana disebutkan dalam Atharva Veda XILI.I yaitu :

"Satyam brhad rtam ugram diksa, tapo,

Brahma Yajna prthiwimdharuvani”.

\section{Artinya :}

Sesungguhnya satya, rta, diksa, tapa, brahma dan Yajna yang menyangga dunia.

Berdasarkan uraian di atas melaksanakan Yajna berarti memelihara tegaknya dunia.Tegaknya dunia berarti terpeliharanya keseimbangan, keselarasan dan keharmonisan.Ini bisa terjadi bilamana terdapat hubungan timbal balik yang harmonis antara manusia dengan Tuhan dan mahluk hidup lainnya, manusia dengan manusia dan manusia dengan lingkungannya atau lazim disebut dengan TriHita Karana, yaitu tiga hal yang menyebabkan kebahagiaan.

Bagi Umat Hindu yang melaksanakan ajaran Bhakti Marga dan Karma Marga hubungan ini diwujudkan dengan pelaksanaan upacara Yajna dengan Upakara sebagai sarananya.Upakara diwujudkan dalam bentuk banten (Sura,1985:28). Banten sebagai Upakara adalah sebagai alat bantu yang nyata (Nyasa) untuk memudahkan dalarn menghubungkan diri dengan Tuhan. Bila kita tinjau dari segi materi dan waktu berYajna.seolah-olah merupakan pemborosan, tetapi kalau ditinjau dari segi rohani dengan Yajna berarti kita telah menunaikan sebagian tugas suci yang menjadi tanggungjawab manusia. Hal ini sejalan dengan bunyi ayat suci Bhagawad Gita XVIII.sloka 5 sebagai berikut:

"Yajnadana tapah karma

Nayaiyam karyam eva tat

Yajno danam tapas caiwa

Pavanani manisinam”

Artinya :

Perbuatan Yajna, dana dan tapa jangan dihentikan akan tetapi harus dilakukan karenaYajna,Dana mensucikan orang yang bijaksana (Pandit 1988 : 342).

\section{Keberadaan Pura Meru dan Keberagaman Masyarakat Karang Kecicang}


Pura Meru Karang Kecicang adalah karya agung dari seorang yang bernama Kyai Gusti Ketut Ngui, beliau adalah orang yang sangat dihormati oleh masyarakat karang cicang pada saat itu. Menurut pemaparan Armawa (2013) Kyai Gusti Ketut Ngui sangat dermawan dan memiliki pandangan kedepan terhadap umat hindu yang ada di Karang Kecicang. Beliu berharap masyarakat Hindu di Karang Kecicang mempunyai Tempat Suci untuk untuk menyelenggarakan upacara yadnya. Pada Tahun 1880 Kyai Gusti Ketut Ngui bersama masyarakat Karang Kecicang mulai membangun Pura Meru yang dilakukan secara bertahap dan dilanjutkan oleh putra beliu yang bernama I Gusti Putu Kompiang. Atas jasa dari Kyai Gusti Ketut Ngui dan putranya I Gusti Ketut Kompiang Pura Meru masih ajeg sampai sekarang.

Upacara Pujawali di Pura Meru Karang Kecicang di laksanakan setiap Purnamaning Sasih kedasa, dengan menggunakan Caru Manca Mebayang-Bayang Kebo dalam upakara Butha Yadjna. Pura Meru sudah memiliki dua orang Pemangku yaitu Gusti Mangku Komang Oka dan Jero Mangku Made Getul Arnawa yang bertugas merawat dan mengordidir setiap kegiatan Upacara yang dilaksanakan.

Masyarakat Pengamong Pura Meru Karang Kecicang adalah masyarakat Umat Hindu yang ada di Karang Kecicang yang terhimpun dalam organisasi Krama Pura Meru Lingkungan Karang Kecicang. Kehidupan Masyarakat dilingkungan karang kecicang sangat majemuk yaitu sebagai pegawai negeri di Lingkungan Kantor Pemerintah dan Instansi Swasta, petani, pedagang dan pengusaha (swasta). Berbagai etnik yang tinggal di lokasi penelitian adalah : Suku Sasak (penduduk asli), Suku Bali, Suku Jawa, Suku Bugis Makasar, bahkan juga Suku Cina. Dari segi agama yaitu Islam, Kristen, Hindu dan Budha. Dari kemajemukan kondisi itu, juga memungkinkan adanya penggeseran budaya dan bahkan adanya aktualisasi budaya antar budaya penduduk asli Sasak dengan budaya penduduk pendatang terutama antar suku Bali dengan Suku Sasak. Adanya pencampuran kebudayaan tersebut akan tampak pada setiap pelaksanaan acara keagamaan yang tidak bisa lepas dari unsur budaya kedua belah pihak ( Bali dengan Sasak ). Termasuk didalamnya Upakara Caru Manca Mebayang bayang Kebo yang dalam pelaksanaanya diiringi dengan Tetabuhan Telek yang merupakan keseniaan Suku Sasak.

Tabel 1.1 JUMLAH UMAT BERAGAMA DI LINGKUNGAN KARANG KECICANG

\begin{tabular}{|l|l|l|}
\hline NO & AGAMA & JUMLAH \\
\hline
\end{tabular}




\begin{tabular}{|l|c|c|}
\hline 1 & Islam & 12 jiwa \\
\hline 2 & Hindu & 675 jiwa \\
\hline 3 & Budha & 43 jiwa \\
\hline 4 & Kresten & 20 jiwa \\
\hline 5 & Katolik & 8 jiwa \\
\hline 6 & Jumlah & 758 Jiwa \\
\hline \multicolumn{2}{|c|}{ (Sumber data penduduk kelurahan Cakranegara selatan) }
\end{tabular}

Adapun batas-batas wilayah Lingkungan Karang Kecicang adalah ;

Timur : Karang Deha

Barat : Panaraga

Utara : Karang Kelebut

Selatan : Getap

\section{Bentuk Upakara Caru Manca Mebayang-Bayang Kebo}

Sura (1985 : 28) Bagi umat Hindu yang melaksanakan ajaran bakti marga dan Karama Marga hubungan ini diwujudkan dengan pelaksanaan upacara Yadjna dengan upakara dan sarananya. Upakara diwujudkan dalam bentuk banten seperti dalam upacara Pujawali di Pura Meru lingkungan Karang Kecicang yang menggunakan Caru Manca Mebayang-Bayang Kebo yang berbentuk.

Caru Manca Mebayang-Bayang Kebo menggunakan 5 ekor ayam yaitu ayam bulu putih, ayam bulu putih kuning, ayam bulu hitam, ayam bulu biying, ayam bulu brumbun dan kerbau yang berwarna hitam.Kelima ayam dan kerbau disembelih lalu diambil kulitnya dengan bagian kepala, kaki, sayap, dan ekor masih utuh lengkap dengan bulunya bagian ini dibiarkan mentah yang disebut dengan (bayang-bayang) sedangkan dagingnya digunakan untuk Membuat Ebatan yang berwarna merah yang dibuat dari kelapa parut yang dicampur dengan darah yang berwarna merah mentah, daging ayam yang dicincang dan diberi bumbu selengkapnya, Ebatan warna putih menggunakan kelapa parut dicampur daging ayam yang dicincang dan diberikan bumbu, Sate Asam sate yang dibuat dari daging ayam yang dipotong kecil-kecil lalu ditusuk, Sate Lembat sate yang dibuat dari daging ayam yang ditumbuk halus dicampur dengan kelapa parut. Setelah olahan Caru siap baru ditanding dengan menggunakan Kelatkat yang terdiri dari ebatan merah,ebatan putih, ebatan blimbing, Lawar, balung, darah ayam. Setiap warna ayam di isi dengan olahan yang sama hanya berbeda pada jumlah sate yang jumlahnya harus sesuai dengan urip seperti, ayam putih mulus sebelah timur dengan jumlah sate 5 biji, ayam putih kuning sebelah barat dengan jumlah sate 7 , ayam hitam sebelah utara dengan jumlah sate 4 , ayam being kuning sebelah selatan dengan jumlah sate 9 , ayam brumbun ditengah dengan jumlah sate 8, Caru manca yang sudah di tanding diletakan di atas kulit kerbau yang dilengkapi sarana banten yang diletakan dilima penjuru arah yang di tandai dengan bambu buluh sebagai pengganti sanggah crukcuk dan dilengkapi dengan sarana Banten sebagai berikut (Oka, 2015) 
Sebelah Selatan Jerimpen, tumpeng merah, kojong manak, calon, sampean nagasari, gibungan merah, wakia/daging ayam merah, peras dengen, Sebelah Utara Jerimpen, peras, bayuan, tumpukan, daksina, teenan, tegen tegenan, SebelahTimurJerimpen, peras, bayuan, tumpukan, daksina, teenan, Sebelah Barat Jerimpen, peras, Bayuan tumpukan, daksina, teenan, TengahJerimpen, peras, tumpukan, berassookan, bayuan, air, tuak, arak, berem, teenan”.(Sulastri, 2015)

Ungkapan yang disampaikan oleh sumber tersebut sesui dengan pendapat Wikarman (1998: 24) bahwa Caru panca Sata menggunakan lima ekor ayam dengan warna menurut lima mata angin (pengider-ider). Putih di Timur, Merah atau biying di selatan, Hitam di Utara, Putih Kuning di Barat, dan Brumbun di tengah. Semua ayam dikuliti, diambil bayang-bayangnya. Daging nya diolah menjadi sate asam, sate pusut, uraab merah, urab putih, urab blimbing, dan lawar. Semua jenis Upakara tersebut digelar dengan susunan sebagai berikut :

1. Di hulu dari arel pecaruan itu ditempatkan Banten Upasaksi, dengan eteh-eteh panglukatan, Upakara penelahan ( prayascita, Durmanggala).

2. Di timur Caru Ayam putih di alasi Sengwi yang lembarnya 5 lembar. Di atasnya dibentangkan Bayang-bayang ayam putih, lalu olahan 5 tanding dan diatasnya sege nasi putih 5 tanding dilengkapi dengan Bayuan. Caru ini untuk Sang Kala Bhuta Jangitan.

3. Di Selatan Caru Ayam biying dialasi Sengwi yang lembarnya 9 lembar. Diatasnya Bayangbayang ayam Biying lalu olahan 9 tanding. Diatasnya nasi Sege warna merah 9 tanding, Bayuan. Caru ini untuk Sang Kala Bhuta Langkir.

4. Di Barat Caru ayam putih kuning yang dialasi sengwi 7 lembar dan diatasnya dibentangkan bayang-bayang ayam putih kuning, lalu dilengkapi olahan 7 tanding. Di atasnya Sege nasi kuning 7 tanding, Bayuan. Caru ini untuk Sang Kala Bhuta Lembukany.

5. Di Utara Caru ayam hitam yang dialasi Sengwi 4 lembar, diatasnya dibentangkan Bayangbayang ayam hitam lalu disusun olahannya 4 tanding dan Sege nasi hitam 4 tanding, dilengkapi bayuan. Caru ini untuk Sang Kala Bhuta Karuna.

6. Di Tengah Caru ayam Brumbun dialasi Sengwi 8 lembar dan diatasnya dibentangkan Bayang-bayang ayam brumbun disusun dengan olahannya 8 tanding dilengkapai dengan Sege nasi Manca warna. Caru ini untuk Sang Kala Tiga Sakti.

Bagi Umat Hindu yang melaksanakan ajaran Bhakti Marga dan Karma Marga hubungan ini diwujudkan dengan pelaksanaan upacara Yajna dengan Upakara sebagai sarananya. Upakara diwujudkan dalam bentuk banten. Banten sebagai Upakara adalah sebagai alat bantu yang nyata (Nyasa) untuk memudahkan dalarn menghubungkan diri 
dengan Tuhan (Sura, 1985: 28).

a. Mandi Darah

Widana ((2001 : 75) Hakikat yadjna itu sendiri adalah realitas bakti yang dilandasi hati yang bersih, suci, dan tulus iklas. Pelaksanaan yadjna lebih menekankan pada kwalitas dan bukan kwantitas kerena dalam proses yadnya itu sendiri akan berlangsung hukum simbiosis mutualisme, yakni berbagai komponen dan potensi akan berputar dan berakibat pada kerahayuan dan kerahajengan bersama.

Pada saat Pecaruan di Pura Meru Karang Kecicang juga dilakukan upakara Mandi Darah yang dilakuklan oleh Pemangku tempat. Pemangku berdiri diatas kepala kerbau, lalu dimandikan dengan darah kerbau yang sudah dicampur dengan air, yang mana darah kerbau yang akan dipakai memandikan Pemangku hanya boleh ditaruh pada tempat yang terbuat dari pelahpah daun pinang kering. Setelah pemangku dimandikan dengan darah pemangku dibolehkan pulang dengan berjalan mundur. Tujuan dari mandi darah adalah untuk memohon panugrahan ida sanghyang widi wasa agar diberikan kekuatan, kesucian seperti bayi yang baru lahir setelah itu pemangku baru diperbolehkan mudalan ida batare. (Arnawa, 2015)

Ungkapan yang disampaikan oleh impormen sesui dengan pernyataan (Kniten, 2005 : 3) yang menyatakan korban darah yang dipergunakan dalam upacara Agama. Mengapa harus mempergunakan darah sebagai korban kepada Butha (butha yadnya). Darah yang dianggap suatu zat yang mengandung kekuatan magis, memberikan kekluatan secara spritual. Hal ini dapat kita tinjau dari pemelaspas bangunan. Pada waktu melaspas diberikan pengurip urip yang dipoleskan pada tiang-tiang, tembok dengan darah yang mempunyai makana agar bangunan tersebut mempunyai kekuatan spritual, sehingga rumah tersebut memberikan suasana yang baik. Darah berfungsi penting dalam melaksanaan kurban kepada Butha Kala, Setiap bentuk Butha yadjna mempergunakan darah.

\section{b. Pengastawa Caru Manca Mebayang-Bayang Kebo}

Titib (2001 : 12) menyatakan bahwa menggunakan mantra dalam pelaksanaan upacara agama sangat berguna untuk menambah keyakinan dalam pendekatan diri terhadap Ida Hyang Widhi Wasa. Mantra artinya ucapan yang keluar dari pikiran (manah) dan pikiran merupakan saluran membentuk rupa atau wujud yang dapat dibayangkan.Seluruh kitab SrutisSyairnya pada umumnya disebut mantra meliputi seluruh kitab-kitab Samhita (Catur Weda), Brahmana, Aranyaka dan kitab-kitab Itihasa (Ramayana dan Mahabharata) termasuk kitab Bhagawandgita.Di Bali menyebut setiap syair berbahasa Sansekerta yang 
disebut mantra sedangkan doa puja yang menggunakan bahasa Bali disebut Sehe.

Adapun makna pengucapan mantra dapat dirinci yaitu untuk mencapai kebebasan, menuju manifestasi Tuhan Yang Maha Esa, menuju para Dewa dan roh-roh, berkomunikasi kepada para Dewa, memperoleh tenaga dari manusia super (purusottama), menyampaikan persembahan kepada roh leluhur dan para Dewa, berkomunikasi kepada roh-roh, mencegah pengaruh negatif, memberi pengaruh lain terhadap pikiran dan perbuatan (Titib, 2000: 467). Umat Hindu percaya bahwa kehidupan ini meliputi dan diresapi oleh mantra. Adapun makna sebuah mantram adalah suatu ucapan yang mempunyai kekuatan yang luar biasa yang dapat mengkonsentrasikan pikiran untuk meningkatkan kekuatan supra natural pada diri manusia.Pikiran yang luar biasa dapat memuncak darimantra disertai dengan meditasi. Mantra dapat meningkatkan Sradha dan Bhakti bagi umat Hindu, dalam melakukan persembahyangan.

Seperti dalam Upakara Caru Manca Mebayang-Bayang Kebo yang dilaksanakan di Pura Meru Lingkungan Karang Kecicang juga menggunakan Mantram Pulasari (2009: 184) Sebagai berikut :

Om Sang Bhuta Baruna, purwa desa nira, umanis panca warnania. Iti sajah sajinira panek puti ayam puti, rinacaca winangun urip, ajaken wadwa kalanira limang atus limang puluh lima, anadah ta sire, wusre atatanjan, mantuk sire ring khyangan sowang-sowang. Ang sang Namah.

Om Bhuta Janggitan, daksina desanir, pahing panca warna nia, Brahma dewatannia. Iti tadah sajineira penek bang, ayam wiring winangurip, ajakan wadwadnira sangangatus, sangang puluh sanga, anadah ten sire wisire amanganginum satetanjan, mantuk pwa sire ring kayangan nira sowangsowang.Om Bang Namah.

Om Bhuta Lembu Kanya, pascima desanira, pon panca nira, Mahadewa dewatania. Iti sajah sajinire penek kuning ayam buik rinancana nangun urip, ajakan wadwa kala nira pitung atus pitu,puluh empat, anadah ta sire wisire amangananginum sate tanjan, mantuk pwa sira ring kayangan nira sowang-sowang. Ong Tng Namah.

Om Sang Bhuta Aruna, Utara desanira, wisnu dewatania, iti tadah sajinepenek ireng ayam ireng rinacana winangun urip, ajakan wadwa kala nira petangatus petang puluh pat, anadah ta sira wasira anadah amanganginum satetanjam mantuk pwa sira ring kayangan nira sowang-sowang, Ong Ang Namah.

Om Pakulun sira sang butha tiga sakti, madya desa nira, kliwon panca warnaniaa, batara Siwa Dewatania. Iti tadah sajenire panek amanca warna, iwak ayam isa,rinancana winangun urip, ajakalen kala wadwanira walungatus wulung puluh wolu, wusire anadah tasire, wusire anadah amangamanginum satetanjen, mantuk pwe sire ring kayangan nira sowang-sowang. Ong Ing Namah. 


\section{Makna Upakara Caru Manca Mebayang-Bayang Kebo}

a. Mensucikan Pikiran

Manusia adalah salah satu mahluk berfikir untuk mencapai kesempurnaan hidup. Manusia senantiasa dihadapkan pada dua pilihan yang bersifat kontradiktif, yaitu kebajikan (subhakarma) dan kebatilan (asubhakarma). Hal ini sejalan dengan pandangan teori analisis bahwa ada unsur-unsur dinamis dan kontradiktif pada diri manusia. Seperti hal nya pendapat Carl Gustav Jung (dalam Suryosumunar, 2019) bahwa sistem psyche (kepribadian) manusia tersusun dari berbagai pertentangan yang membentuk suatu keteraturan dalam sistem tersebut. Dalam hal ini kutub positif dan kutib negative saling beradu, dimana kebajikan dan kebatilan berhadap-hadapan sebagai kedua kutub yang berlawanan secara total dan tidak bisa didamaikan. Sehubungan dengan ini manusia dituntut agar mampu melaksakan pilihan hidup yang tepat, karena pilihan yang salah akan membawa konsekuensi yang fatal. Oleh karena itu, manusia dituntut untuk hidup bertanggung jawab dengan memperhatikan berbagai konsekwensi (pahala) seperti yang diajarkan dalam Karmapala dan Samsara (Sudarsana, 2005: 51):

"Makna Upakara Caru Kebo adalah untuk mensucikan pikiran kita dari pengaruh kekuatan buta kala yang bersipat negatip yang akan menyebabkan orang melakukan perbuatan-perbutan yang bertentangan dengan moralitas sehingga dapat merugikan diri sendiri dan orang lain"(Arnawa, Hasil wawancara,25 Maret 2015)

"Makna filosopi Upakara Caru Kebo adalah untuk meningkatkan kwalitas berpikir kita agar selalu berpikir positip, dengan Upacara yadjna seperti UpakaraCaru Kebo akan memberi kekuatan positif pada pikiran kita dengan demikian sipat-sipat mahluk buta tidak akan berpengaruh"(Regep, Hasil Wawancara, 25 maret 2015)

"Makna Filosopi Upakara Caru kebo adalah untuk menyerap kekuatan/energi ketuhanag yang di simbulkan oleh kerbau yang berwarna hitam yang di gunakan dalam upakara yadjna, sehingga setiap orang mempunyai kekuatan untuk bisa menetralisir hal-hal yang tidak baik yang ada dalam pikiran sesorang"(Sabda, Hasil Wawancara,25 maret 2015)

Pendapat yang di kemukakan oleh Imformen sesuai dengan pendapat Sudarsana (2005 : 51) manusia sebagai mahluk yang tertinggi tingkat eksistensinya (dalam arti tinggi 
atau rendahnya status manusia sebagai makluk) ditentukan oleh mutu perbuatan (karma) secara keseluruhan dalam kehidupan sekarang. Perbuatan (karma) bertanggung jawab atas status dan nasib Atma dikemudian hari.Semakin tinggi perbuatan seseorang semasa hidupnya, dalam arti bahwa neraca kehidupan moralnya lebih banyak ditandai dengan kebajikan (subhakarma), semakin tinggi pula hasil (pahala) yang diterimanya.Dan sebaliknya semakin rendah mutu perbuatan seseorang semasa hidupnya, dimana neraca moralnya menunjukan bahwa kebatilan (asubhakarma) lebih berat timbangannya dari kebajikan (subhakarma) semakin rendah pula pahala yang diterimanya. Kalau ini terjadi, maka Atma akan menjelma kembali sebagai mahluk yang lenbih rendah derajatnya dari manusia.

Manusia sebagai pengemban dharma, manusia adalah ciptaan Tuhan yang derajatnya paling tinggi bila dibandingkan dengan mahluk-mahluk lain. Disamping itu menjelma sebagai manusia merupakan suatu pahala dan sekaligus sebagai kesempatan emas untuk meningkatkan mutu kehidupan melalui karma yang baik agar tercapai kebahagiaan dan kesejahteraan hidup, kedamaian dan kelestarian ciptaan Tuhan (jagaddhita).Bila dapat secara sempurna melaksanakandharma (ajaran agama) di dalam mencapai Jagaddhita, manusia dapat melepaskan diri dari samsara, yaitu mencapai kebahagiaan abadi atau penyatuan Atma dan Brahman, yang juga dikenal sebagai moksa.

Manusia adalah salah satu mahluk berfikir untuk mencapai kesempurnaan hidup.Manusia senantiasa dihadapkan pada dua pilihan yang bersifat kontradiktif, yaitu kebajikan (subhakarma) dan kebatilan (asubhakarma).Di sini kebajikan dan kebatilan berhadap- hadapan sebagai kedua kutub yang berlawanan secara total dan tidak bisa didamaikan. Sehubungan dengan ini manusia dituntut agar mampu melaksakan pilihan hidup yang tepat, karena pilihan yang salah akan membawa konsekwensi yang fatal. Oleh karena itu, manusia dituntut untuk hidup bertanggung jawab dengan memperhatikan berbagai konsekwensi (pahala) seperti yang diajarkan dalam Karmapala dan Samsara.Dalam konteks ini, memang manusia diciptakan sebagai satu-satunya wujud dalam universal ini yang dianugrahi kemampuan untuk dapat membedakan antara yang benar dengan yang salah, yang baik dan yang buruk, yang bermanfaat dan yang merugikan, yang menyenangkan dan yang menyusahkan. Oleh karena itulah pikiran menjadi motor dan sekaligus pusat kehidupan manusia. Menurut Puja (1985 : 49):

"Kunang sangksepanya, manah nimitaning niscayajnana, dadi pwang niscayajnana, lumekas tang ujar, lumekas tang maprawertti, matangyan manah ngaranika 
pradhana mangkanan."

Artinya :

Adapun kesimpulan, pikiran yang merupakan unsur yang menentuikan, jika penentuan perasaan hati telah terjadi, maka mulailah orang berkata atau melakukan perbuatan. Oleh karena itu pikiranlah yang menjadi pokok sumbernya.

Agama Hindu memberikan tuntutan yang amat jelas, tegas, dan transparan terhadap umatnya bersama nilai holistik Hindu yang dapat memberikan insprasi terhadap kelestarian lingkungan beberapa diantaranya adalah makna pemanfaatan alam untuk tujuan kesejahteraan bersama melalui pemanfaatan pengetahuan intelektual, dan akal budi manusia merupakan suatu yang sah, wajar dan sepatutnya dilakukan. Akan tetapi perusakan lingkungan fisik alam terlebih-lebih tidak untuk kesejahteraan bersama, jelas dan tegas dilarang. Keyakinan akan adanya kebersamaan bhuwana Alit (mikrokosmos) atau sistem holistik diri sendiri insan personal manusia dan relasinya dengan Bhuwana Agung (makrokosmos) sistem holistik galaksi alam raya, secara inplisit merupakan pengakuan akan keyakinan bahwa tertanggungnya keseimbangan sistem holistik alam raya, dimana bumi yang akan mengganggu keseimbangan internal batin manusia.

Pada hakikatnya manusia adalah mahluk biologi, mahluk pribadi, mahluk sosial dan sekaligus pendukung kebudayaan di atas bumi.Manusia di samping memiliki potensi dan juga ada tntangan untuk dapat mempertahankan kehidupannya.Untuk mempertahankan hidupnya, manusia menggunkan pikiran dan akal budinya serta dengan data-data emperisnya mampu merekam masa lampu sehingga melahirkan ide-ide untuk mengatasi tantangan alam yang ada didunia ini.

\section{b. Harmoni Alam}

Pelaksanaan Upakara Caru Manca Mebayang-Bayang Kebo ini merupakan suatu usaha yang mulia dan terhormat sebab didalamnya terkandung makna pemeliharaan terhadap kekuatan alam semesta (Bhuta Kala), walaupun kedudukannya lebih rendah daripada manusia, oleh karena perlunya para Bhuta Kala itu diberikan korban suci.Berupa caru demi keselamatan, keharmonisan dan kesejahteraan alam semesta (Bhuana Agung). Demikian pula halnya dengan manusia (Bhuana Alit) perlu disucikan, tubuh manusia terdiri atas unsur-unsur Panca Maha Bhuta, yang menyebabkan manusia bingung, marah, lobo, keras dan sebagainya yang merupakan ciri-ciri dari Bhuta Kala (Sudarsana, 2005 
:46).

"Makna dari Upakara Caru Kebo adalah untuk menjaga keseimbangan alam Buana alit dan Buana Agung karena keduanya terikat hukum saling membutuhkan satu sama lain. Bila terjadi ketimpangan dibuana alit akan menimbulkan perbuatan yang kurang baik yang akan merugikan masyarakat dan lingkungan sekitarnya"(Arnawa,2015).

"Makna yang terkandung dalam Upakara Caru Kebo yaitu untuk menyelaraskan buana agung dan buana alit yang mana keduanya berasal unsur yang sama yaitu Panca Mahabuta dan saling membutuhkan. Manusia hidup dari alam dan sebaliknya alam sangat membutuhkan manusia untuk menjaga dan melestarikannya namun bila manusia berada dalam pengaruh sipat buta kala akan merugikan dan mengganggu keseimbangan alam samasta”( Sabda, 2015)

Pernyataan dari Imforman sesuai dengan pendapat Sudarsana (2015: 51) yang menyatakan Keseimbangan hidup antara manusia dan alam lingkungan merupakan refleksi dari konsep Trihita Karana yang di wujudkan melalui upacara yang di sebut butha yadnya. Upakara Butha yadjna ini bermakna sebagai korban suci yang bertujuan untuk membersihkan alam samasta beserta isinya dan memelihara serta memberi penyupatan kepada para butha kala dan mahluk-mahluk yang di anggap lebih rendah dari manusia seperti kehidupan mahluk asral/mahluk halus, Binatang dan tumbuhan. Konsepsi ini didasari oleh ide kesatuan, yakni manusia mesti menyatukan diri dengan alam secara serasi, selaras dan seimbang. Dalam konsep tersebut dinyatakan bahwa Manusia (bhuana alit) dan alam (bhuana agung) tersusun oleh unsur yang sama.

Adapun penyusunan bhuana alit (mikrokosmos) dan bhuana agung (makrokosmos) adalah lima unsur pokok alamiah yang di sebut dengan Panca Mahabhuta yang terdiri dari unsur padat (petiwi), unsur cair (apah), unsur panas (teja), unsur udara (bayu), unsur ruang (akasa) serasinya hubungan antara manusia dengan alam dapat diumpamakan dengan pernyataan "kadi manik ring cecupu”. Manusia di umpamakan sebagai manik (janin) sedangkan alam sebagai cecupu (rahim). Konsep ini mengandung makna bahwa manusia hidup dilingkupi oleh alam dan dari alamlah manusia memperoleh sarana untuk hidup. Manusia bebas mengambil dan memanfaatkan apa saja dari alam. Tetapi ia diikat kewajiban untuk memelihara alam karena jika alam rusak, maka manusiapun tidak luput dari bencana dan terkena langsung dampak kerusakan tersebut. Salah satu caranya dengan melakuakan yadjna Upakara Caru Manca Mebayang-Bayang Kebo di Pura Meru Karang Kecicang cakranegara Selatan. yang merupakan satu rangkaian dengan upacara Pujawali Pura Meru. 


\section{Kesimpulan}

Berdasarkan basil analisa data dan rumusan masalah yang penulis sajikan diatas, penulis dapat mengambil kesimpulan bahwa :

1. Bentuk Caru Manca Mebayang-Bayang Kebo di Jaba Pura Meru Karang Kecicang Cakranegara adalah merupakan dari panca Yajna, yaitu dari Bhuta Yajna yang artinya koban suci kepada mahluk halus, yang berdasarkan kepercayaan dinamakan dengan Bhuta Kala, yang sering mengganggu kehidupan masyarakat.

2. Fungsi dari Caru Manca Mebayang-Bayang kebo adalah untuk penyucian diri dan penyupatan Bhuta Kala, yaitu mahluk yang dianggap lebih rendah dari manusia, seperti: Peri, Jin, Setan, binatang termasuk tumbuh-tumbuhan dan lain sebagainya. Hal tersebut dilakukan untuk tetap menjaga keharmonisan hidup.

3. Makna dari Upakara Caru Manca Mebayang-bayang Kebo agar manusia menyadari bahwa dalam diri manusia ada pengaruh dari sifat buta kala yang akan menyebabkan manusia melakukan kesalahan dan dengan melaksanakan upakara yadnya manusia akan mempunyai kekuatan positip untuk menetralisir pengaruh dari mahluk buhta tersebut.

\section{Daftar Pustaka}

Arwati, Made Sri. (1982). Sekelumit Tentang Dhurgamahisa Suramardini. Widya Dharma majalah Dua Bulanan Institut Hindu Dharma.Hal:29-30

Astra, Semadi, dkk. (2000). Kamus Sansekerta Indonesia, Milik pemerintah Propinsi Bali Proyek Peningkatan Sarana Prasarana Kehidupan Beragama Terbesar di 9 (Sembilan) Kabupaten / Kota Tahun 2000.

Mardiwarsito.I. (1981). Kamus Jawa Indonesia, Nusa Indah: Ende - Flores.

Mantra, I.B. (1992). Tata Susila Hindu Dharma, Cetakan II. PT. Gramedia: Jakarta

Somawati, A. V., \& Made, Y. A. D. N. (2019). Implementasi Ajaran Tri Kaya Parisudha Dalam Membangun Karakter Generasi Muda Hindu Di Era Digital. Jurnal Pasupati Vol, 6(1).

Suamba, Ida Bagus Putu. (1996). Yadya Bazis Kehidupan (Sebuah Canang Sari) Warta Hindu Dharma: Denpasar. 
Suryosumunar, J. A. Z., \& Noorzeha, F. (2021). Antonio Gramsci’s Perspective on

Dominant Culture and Social Media's Impact in the Era of Globalization in Indonesia. Journal of US-China Public Administration, 18(1), 38-46.

Suryosumunar, J. A. Z. (2019). Konsep Kepribadian dalam Pemikiran Carl Gustav Jung dan Evaluasinya dengan Filsafat Organisme Whitehead. Sophia Dharma: Jurnal Filsafat Agama Hindu dan Masyarakat, 2(1), 18-34.

Titib, I Made. (2000).Teologi \& Simbol-simbol Dalam Agama Hindu, Surabaya Paramita (2001).Veda dan Susastra Hindu (Studi Sumber Ajaran Hindu) Makalah

Disampaikan Pada Matrikulasi Maha Siswa Baru Tanggal 27 Agustus s/d 7 September 2001 : Program Pascasarjana STAH Negeri Denpasar.

Wojowasito. S. (1977). Kamus Kawi-Indonesia. CV.Pengarang: Surabaya

Wikarman, I Nyoman Singgih. (1994). Caru. Yayasan Wdya Santhi: Bangli 